\title{
Characterization of Proteins Responsive to Gibberellin in the Leaf-Sheath of Rice (Oryza sativa L.) Seedling Using Proteome Analysis
}

\author{
Shihua Shen, Arun Sharma, and Setsuko Komatsu* \\ Department of Molecular Biology, National Institute of Agrobiological Sciences; 2-1-2 Kannondai, Tsukuba, Ibaraki \\ 305-8602, Japan. Received July 10, 2002; accepted November 11, 2002
}

\begin{abstract}
In plants gibberellins (GAs) are responsible for triggering stem or internodal elongation. To comprehend the molecular basis of internodal elongation in rice, a proteomics approach using differentially displayed proteins on two-dimensional polyacrylamide gel electrophoresis (2-D PAGE) was carried out to identify the proteins expressed during the GA controlled leaf-sheath elongation response. Out of 352 protein spots detected on 2-D PAGE, 32 proteins showed modulation in the expression levels in $\mathbf{G A}_{3}$-treated leaf-sheath for $48 \mathrm{~h}$ as compared to control. These proteins were analyzed using protein sequencer and/or mass spectrometry in conjunction with the protein database to assign putative identities. The twin protein spots (LS079 and LS083), identified as calreticulin, showed different isoelectric points and expression level in $\mathbf{G A}_{3}$-treated leaf-sheath. The expression level of LS083 (pI 4.0) was down-regulated as compared to the up-regulation of LS079 (pI 4.3). In the presence of $\mathrm{GA}_{3}$ and growth inhibitor, uniconazole and abscisic acid, respectively, no elongation in leaf-sheath occurred and calreticulin did not shift from LS083 to LS079. Over-expression of calreticulin in rice inhibited the callus regeneration and seedling growth. These results suggest that calreticulin is an important component in the GA signaling pathway that regulates rice seedling leaf-sheath elongation.
\end{abstract}

Key words rice; leaf-sheath; gibberellin; two-dimensional polyacrylamide gel electrophoresis; matrix-assisted laser desorptionionization time-of-flight mass spectrometry; calreticulin

The phytohormone gibberellins (GAs) are essential endogenous regulators of plant growth and developmental processes including seed germination, stem elongation, leaf growth, cell division, flowering and fruit development. ${ }^{1,2)}$ In recent years, significant progress has been made in understanding the pathways involved in GA biosynthesis and on the mechanisms by which GA levels are regulated in plants. ${ }^{3)}$ Despite this progress, the potential elements involved in GA perception and signal molecules that are transduced to control GA-regulated gene expression are still elusive. Although, recent advances in molecular and pharmacological studies in cereal aleurone have proposed the role of $\mathrm{Ca}^{2+}$, calmodulin, cyclic GMP, heterotrimeric $\mathrm{G}$ proteins, and protein kinases in GA signaling, ${ }^{4)}$ little is known of what occurs between the step that follows GA binding to its receptor and the activation of the target genes.

The biological functions of GAs have been well documented by genetic and physiological approaches analyzing GA-response mutants, and more than 60 genes that participate in plant growth are known. ${ }^{5)}$ The best characterized dwarf mutant $\mathrm{d} 1$, in rice is deficient in GA perception, shows semi-dwarf phenotype, and is unrescuable by adding exogenous GA, implying that this gene may encode positive regulators of the GA signal transduction pathway. ${ }^{\text {() }}$ Also, the slender mutant in rice caused by loss-of-function mutation of the SLR1 gene, a negative regulator of GA signaling, was characterized by its rapid growth and long leaf-sheath in response to GA and abscisic acid (ABA) biosynthesis. ${ }^{7)}$

Recently, proteomics has become an essential methodology for large-scale analysis of proteins in various fields of plant biology. ${ }^{8}$ Proteomics, in combination with the availability of genome sequence data, has opened up an enormous possibility to identify the total set of proteins as well as their expression levels. ${ }^{9}{ }^{9}$ It provides fundamental insights into organism development and homeostasis that cannot be provided by the genome sequence. ${ }^{10)}$ In addition, proteome analysis using differential display with two-dimensional polyacrylamide gel electrophoresis (2-D PAGE) has several advantages over other approaches commonly used for similar studies, such as efficient separation of complex protein mixtures, analysis of isoforms, or secondary modifications of proteins such as glycosylation and phosphorylation, macromolecular complexes such as protein-ligand, protein-protein, and protein-DNA interactions, and proteolysis using low amounts of proteins. ${ }^{11)}$

In this study we report a systematic analysis aimed at establishing an effective approach to understand the molecular basis for analyzing the GA controlled leaf-sheath elongation response in rice. For this, a proteome map of rice leaf-sheath was constructed using 2-D PAGE, Edman sequencing and matrix-assisted laser desorption-ionization time-of-flight mass spectrometry (MALDI-TOF-MS).

\section{MATERIALS AND METHODS}

Plant Growth Conditions Rice (Oryza sativa L. cv. Nipponbare) seedlings were grown under white fluorescent light (6000 lux, $12 \mathrm{~h}$ light period/d) at $25^{\circ} \mathrm{C}$. Three-cm-long leaf-sheath segments were cut from two-week-old rice seedlings, and floated on a $20 \mathrm{ml}$ solution of $\mathrm{GA}_{3}$, with or without uniconazole $p$ (Un-p), and ABA in sterile plastic petri dishes, and were incubated under a continuous light source in a growth chamber at $25^{\circ} \mathrm{C}$ for various time periods as indicated.

Chemicals $\mathrm{GA}_{3}$ and $\mathrm{ABA}$ were obtained from Wako Pure Chemicals (Osaka, Japan). Un-p was purchased from Agros (Tokyo, Japan). Urea was obtained from ICN (Aurora, OH, U.S.A.), and ampholines were obtained from Amersham Pharmacia Biotech (Uppsala, Sweden). Staphylococcus aureus V8 protease was obtained from Pierce (Rockford, IL, U.S.A.), and trypsin and $\alpha$-cyano-4-hydroxycinnamic acid (CHCA) were from Sigma (St Louis, MO, U.S.A.). 
Protein Extraction and 2-D PAGE A portion $(500 \mathrm{mg})$ of leaf sheaths was homogenized in $1 \mathrm{ml}$ of a homogenization buffer containing $20 \mathrm{~mm}$ Tris- $\mathrm{HCl}(\mathrm{pH} 7.5), 250 \mathrm{~mm}$ sucrose, $10 \mathrm{~mm}$ EGTA, $1 \mathrm{~mm}$ phenylmethylsulfonyl fluoride, 1 mu dithiothreitol (DTT) and $1 \%(\mathrm{v} / \mathrm{v})$ Triton X-100. The homogenates were centrifuged twice at $15000 \mathrm{rpm}$ for $5 \mathrm{~min}$ and for $10 \mathrm{~min}$ in a TMA-4 rotor (Tomy, Tokyo, Japan). The supernatant was precipitated by $10 \%$ trichloroacetic acid on ice for $20 \mathrm{~min}$, followed by centrifugation at $15000 \mathrm{rpm}$ for $10 \mathrm{~min}$. The pellet was suspended in $250 \mu \mathrm{l}$ of a lysis buffer containing $8 \mathrm{M}$ Urea, $2 \%$ Triton X-100, $2 \%$ ampholine (pI $3.5-10), 10 \%$ polyvinylpyrrolidone, and the supernatant (50 $(\mu \mathrm{l})$ was subjected to 2-D PAGE. ${ }^{12)}$ The gel was stained with Coomassie brilliant blue (CBB). The isoelectric point and molecular mass of each protein were calibrated using 2-D PAGE standards (Bio-Rad, Richmond, CA, U.S.A.).

Image Analysis of 2-D PAGE The CBB stained gels were scanned using a flatbed scanner, and the data were analyzed using Image Master 2D Elite software (Amersham Pharmacia Biotech, Uppsala, Sweden).

N-terminal Amino Acid Sequence Analysis 2-D PAGE separation proteins were electroblotted onto a polyvinylidene difluoride (PVDF) membrane (Fluorotrans; Pall BioSupport Division, Port Washington, NY, U.S.A.) using a semi-dry transfer blotter (Nippon Eido, Tokyo) and visualized by CBB staining. The proteins were excised from the PVDF membrane and analyzed with a gas-phase protein sequencer (Model 494, Applied Biosystems, Foster City, CA, U.S.A.).

Internal Amino Acid Sequence Analysis The CBB stained gel containing protein spots was removed, and proteins were electro-eluted from the gel pieces using an electrophoretic concentrator (Amicon, Inc., Beverly, MA, U.S.A.) at $200 \mathrm{~V}$ for $2 \mathrm{~h}$. Thereafter, the protein solution was dialyzed overnight against Milli $\mathrm{Q}$ water. The proteins were dissolved in $20 \mu \mathrm{l}$ of SDS sample buffer (pH 6.8) and applied to sodium dodecyl sulfate (SDS)-PAGE gel. Twenty microliters of Staphylococcus aureus V8 protease $(0.05 \mu \mathrm{g} / \mu \mathrm{l})$ was overlaid on the sample solution. Electrophoresis was performed until the sample and protease were stacked in the upper gel and the current was interrupted for $30 \mathrm{~min}$ to allow digestion of the protein. ${ }^{13)}$ The separated digests were then electroblotted onto the PVDF membrane and subjected to amino acid sequencing as described above. The amino acid sequences were compared with protein sequences in a Swiss-Prot database using the FASTA sequence alignment program. ${ }^{14)}$

Protein Mass Spectrometry The CBB stained protein spots were excised from the gel, washed with $25 \%(\mathrm{v} / \mathrm{v})$ methanol and $7 \%(\mathrm{v} / \mathrm{v})$ acetic acid for $12 \mathrm{~h}$ at room temperature, and destained with $50 \mathrm{~mm} \mathrm{NH}_{4} \mathrm{HCO}_{3}$ in $50 \%(\mathrm{v} / \mathrm{v})$ methanol for $1 \mathrm{~h}$ at $40^{\circ} \mathrm{C}$. Proteins were reduced with $10 \mathrm{~mm}$ DTT in $100 \mathrm{~mm} \mathrm{NH}_{4} \mathrm{HCO}_{3}$ for $1 \mathrm{~h}$ at $60^{\circ} \mathrm{C}$ and incubated with $40 \mathrm{~mm}$ iodoacetamide in $100 \mathrm{~mm} \mathrm{NH}_{4} \mathrm{HCO}_{3}$ for $30 \mathrm{~min}$ at room temperature. The gel pieces were minced and allowed to dry and then rehydrated in $100 \mathrm{~mm} \mathrm{NH}_{4} \mathrm{HCO}_{3}$ with 1 pmol trypsin at $37^{\circ} \mathrm{C}$ overnight. After digestion, the gel slices were washed with $0.1 \%$ TFA in $50 \%(\mathrm{v} / \mathrm{v})$ acetonitrile three times to extract the peptides. The extracted peptides were then desalted using a Zip Tip C 18TM (Millipore, Bedford, MA, U.S.A.). Peptides were co-crystallized 1:1 (v/v) with saturated CHCA prepared in 50\% (v/v) acetonitrile containing 1\% trifluoroacetic acid (TFA). Calibrations were car- ried out using a standard peptide mixture. ${ }^{15)}$ Tryptic peptide masses were measured using a MALDI-TOF MS equipped with a delayed-extraction system (Perseptive BioSystems, Framingham, MA, U.S.A.). The peptide mass fingerprint obtained for each protein digest was analyzed using Mascot software (Matrix Science Ltd., London, U.K.) for protein identification.

Immunoblot Analysis Proteins separated by 2-D- and SDS-PAGE were transferred to PVDF membrane using a semi-dry transfer blotter as described above. They were blocked with $3 \%$ gelatin in a TBS buffer containing $20 \mathrm{~mm}$ Tris- $\mathrm{HCl}, \mathrm{pH} 7.5$, and $0.5 \mathrm{M} \mathrm{NaCl}$ for $1 \mathrm{~h}$, incubated overnight with an antibody raised against calreticulin, ${ }^{16)}$ and then visualized by incubation with horseradish peroxidaseconjugated goat anti-rabbit IgG followed by color development with 4-chloro-1-naphthol (Bio-Rad).

Transformation of Rice Mediated by Agrobacterium Agrobacterium tumefaciens strain EHA101 (a gift from Dr. E. Hood) has been described previously. ${ }^{17)}$ The rice calreticulin gene was introduced into the sense and antisense orientation under the control of the cauliflower mosaic virus (CaMV) 35S promoter in the pIG121-Hm vector (a gift from Dr. K. Nakamura), a binary vector that contains a kanamycin resistance gene (npt) and a hygromycin resistance gene (hpt), and the intron-gus in the T-DNA region. The full-length cDNA of calreticulin ${ }^{18)}$ was introduced into this strain by electroporation. A. tumefaciens was grown on $\mathrm{AB}$ medium at $28^{\circ} \mathrm{C} .{ }^{19)}$ The transformation was done as previously reported. ${ }^{20)}$ The regenerated rice was eventually transferred to soil in pots and grown to maturity in a greenhouse.
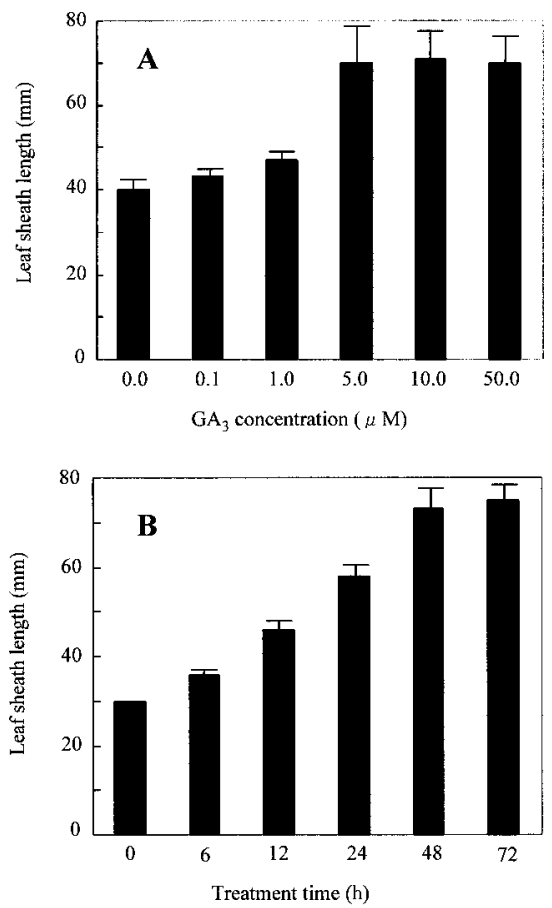

Fig. 1. Effect of $\mathrm{GA}_{3}$ on Leaf Sheath Elongation

(A) Dose dependent elongation of leaf sheath after treatment with $\mathrm{GA}_{3}$. Leaf sheaths excised from two-week-old rice seedlings grown in a $12 \mathrm{~h}$ light $/ 12 \mathrm{~h}$ dark growth chamber at $25^{\circ} \mathrm{C}$ were floated on Milli $\mathrm{Q}$ water containing $0.1,1.0,5.0,10.0$ or $50.0 \mu \mathrm{M}$ $\mathrm{GA}_{3}$, and incubated under continuous light at $25^{\circ} \mathrm{C}$ for $48 \mathrm{~h}$. (B) Time dependent elongation of leaf sheath after treatment with $\mathrm{GA}_{3}$. Leaf sheaths excised from rice seedlings were floated on a $5 \mu \mathrm{M} \mathrm{GA}_{3}$ solution, and incubated for $6,12,24,48$ and $72 \mathrm{~h}$. The mean of three experiments \pm S.E. are shown. 


\section{RESULTS}

Effect of $\mathrm{GA}_{3}$ on Rice Leaf-Sheath Elongation To assess the effective response for the promotion of rice leafsheath elongation by $\mathrm{GA}_{3}$, excised leaf-sheath segments of two-week-seedlings were treated with exogenous $\mathrm{GA}_{3}$ for different time periods as described in Fig. 1. Exogenous application of $\mathrm{GA}_{3}$ in amounts as low as $0.1 \mu \mathrm{m}$ promoted second leaf-sheath elongation, and the effect was saturated at 5 $\mu \mathrm{M}$ after incubation for $48 \mathrm{~h}$ (Fig. 1A). To further examine the kinetics of $\mathrm{GA}_{3}$ action on leaf-sheath elongation, a timecourse experiment was conducted by treating leaf-sheath segments with $5 \mu \mathrm{M} \mathrm{GA}_{3}$ for up to $72 \mathrm{~h}$. The leaf sheath showed significant elongation within $6 \mathrm{~h}$ and peaked within $48 \mathrm{~h}$ of $\mathrm{GA}_{3}$ treatment (Fig. 1B), indicating strongly the role of GAs in the elongation. This result showed that the elongation of the leaf-sheath is strongly stimulated by $5 \mu \mathrm{M} \mathrm{GA}_{3}$ within 48 $\mathrm{h}$ and this parameter was used in subsequent experiments.
Though it has been well documented that GA promotes elongation growth by effecting cell division and expansion ${ }^{1)}$ through activation of histone $\mathrm{H} 1$ kinase and cyclin genes, ${ }^{21}$ physiological and genetic control of elongation has not yet been fully elucidated.

Changes in the Protein Pattern of the Leaf Sheath after $\mathbf{G A}_{3}$ Treatment To determine the proteins related to the $\mathrm{GA}_{3}$ response in rice leaf-sheath, and to identify the various proteins contributing to the leaf-sheath elongation response, the proteins were compared by differential display analysis. They were extracted from leaf-sheaths treated in the presence or absence of $\mathrm{GA}_{3}$. As illustrated in Fig. 2A, a large number of protein spots were found separated on 2-D PAGE gel stained with CBB. Most of the proteins from control and $\mathrm{GA}_{3}$-treated samples were separated with the same electrophoretic mobility on a 2-D PAGE, which was evident using internal protein markers, employed to calibrate proteins according to their molecular mass and isoelectric
A

A

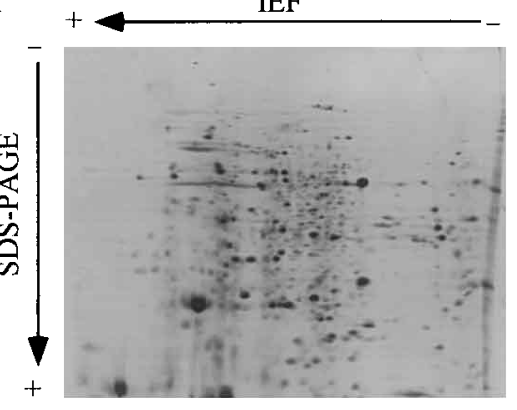

Control

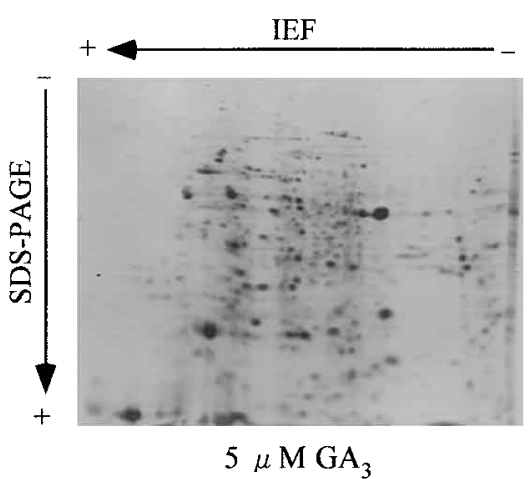

$5 \mu \mathrm{M} \mathrm{GA}_{3}$

B

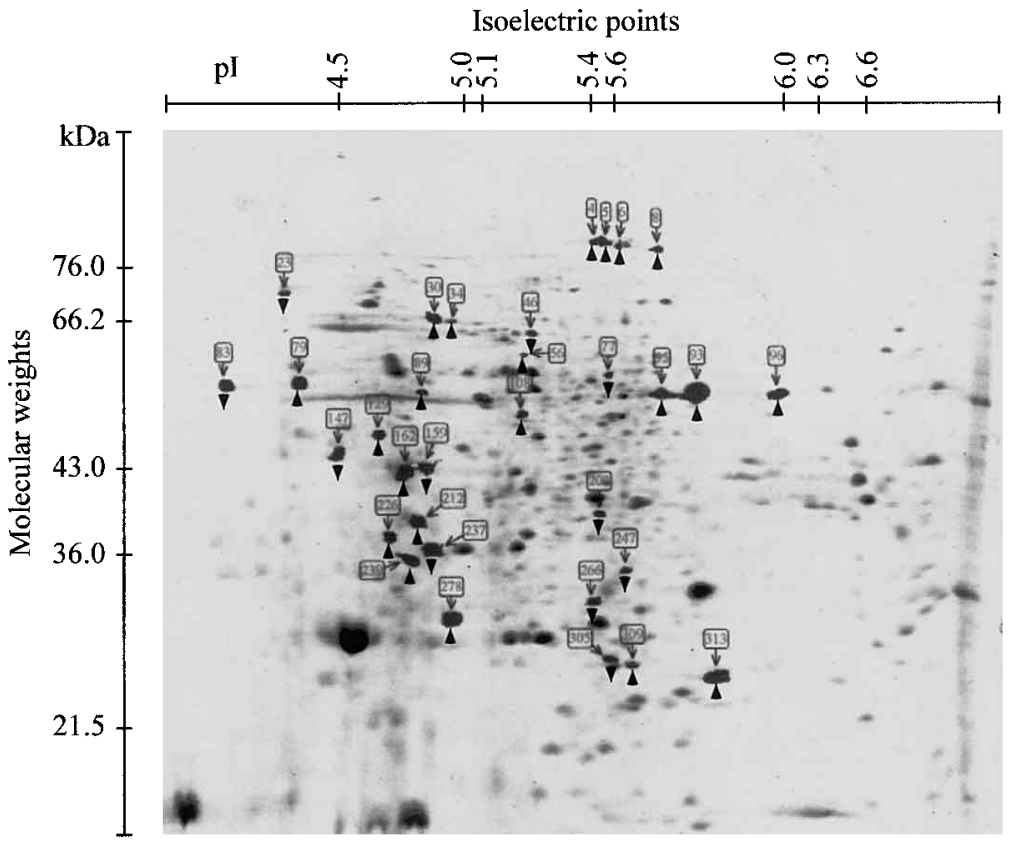

Fig. 2. 2-D PAGE Pattern of Leaf Sheath Proteins from Rice Seedlings

(A) Proteins were extracted from leaf sheaths incubated for $48 \mathrm{~h}$ in $5 \mu \mathrm{M} \mathrm{GA}$, and separated by 2-D PAGE. (B) Proteins were calibrated for isoelectric point and molecular mass by 2-D PAGE standards, and image analysis was carried out using Image Master $2 \mathrm{D}$ Elite software. Changes in number of proteins were found in leaf sheaths treated with $\mathrm{GA}_{3} ; 21$ proteins were enhanced (indicated by triangles), while 11 proteins decreased (indicated by inverted triangles). Right to left: isoelectric focusing for the first dimension; top to bottom: SDS-PAGE for the second dimension. 
Table 1. Identification of Rice Leaf Sheath Proteins by Protein Sequencer and Mass Spectrometry

\begin{tabular}{|c|c|c|c|c|c|}
\hline Spot No. & $\mathrm{kDa}$ & $\mathrm{pI}$ & Homologous protein & Homology (\%) & Accession \\
\hline LS004 $(+)$ & 80.5 & 5.4 & Putative phosphatidylinositol 4-kinase ${ }^{a)}$ & 17 & AAK 18831 \\
\hline $\operatorname{LS} 005(+)$ & 80.5 & 5.5 & Unknown & & \\
\hline $\operatorname{LS} 006(+)$ & 80.5 & 5.6 & Hypothetical protein ${ }^{a)}$ & 37 & BAA95862 \\
\hline \multirow[t]{2}{*}{ LS008 (+) } & 80 & 5.7 & Calcium-binding protein 1 & 85.7 & P42529 \\
\hline & & & Putative glycine dehydrogenase ${ }^{a)}$ & 12 & BAB39424 \\
\hline LS023 (-) & 72 & 4.2 & Unknown & & \\
\hline $\operatorname{LS} 030(+)$ & 67 & 4.8 & Lumenal binding protein & 100 & AAB63469 \\
\hline LS034 $(+)$ & 66 & 4.9 & Lumenal binding protein & 100 & AAB63469 \\
\hline LS046 (-) & 63 & 5.2 & Unknown & & \\
\hline $\operatorname{LS} 056(+)$ & 61 & 5.2 & Unknown & & \\
\hline LS077 (-) & 57 & 5.5 & Unknown & & \\
\hline $\operatorname{LS} 079(+)$ & 56 & 4.3 & Calreticulin & 100 & BAA 88900 \\
\hline \multirow[t]{2}{*}{ LS083 (-) } & 56 & 4.0 & Calreticulin & 100 & BAA 88900 \\
\hline & & & Calreticulin $^{a}$ & 40 & BAA 88900 \\
\hline LS089 (+) & 55 & 4.8 & Tubulin $\alpha-1$ chain & 100 & P28752 \\
\hline \multirow[t]{2}{*}{ LS093 (+) } & 53.5 & 5.8 & RuBisCO large subunit & 100 & P12089 \\
\hline & & & RuBisCO large subunit ${ }^{a)}$ & 21 & P12089 \\
\hline \multirow{2}{*}{$\operatorname{LS} 095(+)$} & 53 & 5.7 & RuBisCO large subunit & 100 & P12089 \\
\hline & & & RuBisCO large subunit ${ }^{a)}$ & 16 & P12089 \\
\hline LS096 (+) & 53 & 6.1 & Unknown & & \\
\hline LS108 (+) & 47 & 5.3 & Unknown & & \\
\hline $\operatorname{LS} 129(+)$ & 46 & 4.6 & RuBisCO activase & 100 & P93431 \\
\hline $\operatorname{LS} 147(-)$ & 45 & 4.5 & Unknown & & \\
\hline $\operatorname{LS} 159(-)$ & 43 & 4.8 & Sorbitol dehydrogenase & 75 & Q02912 \\
\hline $\operatorname{LS} 162(+)$ & 42 & 4.7 & RuBisCO activase & 100 & P93431 \\
\hline $\operatorname{LS} 208(-)$ & 38 & 5.5 & Elongation factor & 85.7 & P42480 \\
\hline $\operatorname{LS} 212(+)$ & 38 & 4.7 & Hypothetical $46.8 \mathrm{kDa}$ protein & 88.9 & P31545 \\
\hline $\operatorname{LS} 226(+)$ & 37 & 4.6 & Unknown & & \\
\hline $\operatorname{LS} 237(-)$ & 36 & 4.9 & Oxygen-evovling enhancer protein 1 , precursor & 100 & P27665 \\
\hline $\operatorname{LS} 239(+)$ & 35 & 4.8 & $5^{\prime}, 5^{\prime \prime \prime}-\mathrm{P}-1, \mathrm{P}-4$-tetraphosphate phosphorylaseII & 70 & P49348 \\
\hline $\operatorname{LS} 247(-)$ & 34 & 5.6 & Unknown & & \\
\hline $\operatorname{LS} 266(-)$ & 31 & 5.5 & Unknown & & \\
\hline $\operatorname{LS} 278(+)$ & 29 & 5 & Ascorbate peroxidase & 100 & BAB 17666 \\
\hline $\operatorname{LS} 305(-)$ & 26 & 5.5 & Hypothetical protein $^{a}$ ) & 38 & BAA90380 \\
\hline \multirow[t]{2}{*}{$\operatorname{LS} 309(+)$} & 25 & 5.6 & G-box binding factor 4 & 66.7 & P42777 \\
\hline & & & GSH-dependent dehydroascorbate reductase $1^{a}$ ) & 72.8 & BAA90672 \\
\hline $\operatorname{LS} 313(+)$ & 24 & 5.8 & Histone $\mathrm{H}^{a}{ }^{a}$ & 32.0 & S59589 \\
\hline
\end{tabular}

$\mathrm{N}$ : N-terminal amino acid sequence. I: Internal amino acid sequence. +: The proteins increased by $\mathrm{GA}_{3}$ treatment. $-:$ The proteins decreased by GA 3 treatment. $a$ ) Data obtained from mass spectrometry.

points. ${ }^{22)}$ In conjunction with the automated gel scanner and computer-aided Image Master 2D Elite software, more then 352 protein spots were detected. Of these, 32 proteins showed modulation in the expression levels in $\mathrm{GA}_{3}$-treated leaf-sheath as compared to control. Among them, the amounts of 21 proteins were up-regulated and those of 11 were down-regulated (Fig. 2 B).

Identification of the Proteins Modulated by $\mathrm{GA}_{3}$ Treatment The 32 proteins showing modulation in the expression level were subjected to N-terminal and internal-amino acid sequence analysis as described in Materials and Methods. The sequence information of 20 proteins (LS008, LS023, LS030, LS034, LS046, LS079, LS083, LS089, LS93, LS095, LS129, LS159, LS162, LS208, LS212, LS226, LS237, LS239, LS278 and LS309) was compared with protein sequences present in the various public databases using FASTA. Seventeen proteins showed similar or identical amino acid sequence homology to the known proteins from plant and other organisms (Table 1). The sequences of 11 of these (LS030, LS034, LS079, LS083, LS089, LS093, LS095, LS129, LS162, LS208 and LS278) were identified as putative rice proteins using various public databases.

Identification of Calreticulin by Edman Sequencing and Mass Spectrometry Of the 32 predicted proteins modulated by $\mathrm{GA}_{3}$ response, LS079 and LS083 were found to be homologous in calreticulin, an endoplasmic reticulum located $\mathrm{Ca}^{2+}$-binding protein. ${ }^{18)}$ Further detailed analysis was made to demonstrate the efficacy of the proteomics approach and to unravel the true identity of these twin spots. Though their molecular mass was $56 \mathrm{kDa}$, the same as that of calreticulin as demonstrated earlier by our group,${ }^{18)}$ the isoelectric point of LS079 and LS083 was 4.3 and 4.0, respectively.

To further assess the identification of LS079 and LS083, the digested peptide fragments of spot LS083 were extracted from 2-D PAGE and their masses were measured by MALDI-TOF MS (Fig. 3A). The peptide masses obtained, were compared with the masses of the predicted tryptic peptides from the database. Fourteen fragments of the measured peptides from spot LS083 matched with the rice calreticulin covering $40 \%$ of the protein sequences (Fig. 3A). Similarly, five Edman sequence tags from spot LS083 were analyzed showing amino acid motifs identical to rice calreticulin. One peptide tag (EVFFQEKFED) was identified as the N-terminal amino acid residues from 30 to 39 (Fig. 3B). The internal sequence of protein LS083 revealed homology to four peptide tags of rice calreticulin (Fig. 3B): the tag I-a sequence FSNKDKTLVL (residues from 94 to 103), the tag I-b sequence AKKPEDWDDK (residues from 223 to 232), the tag 
A

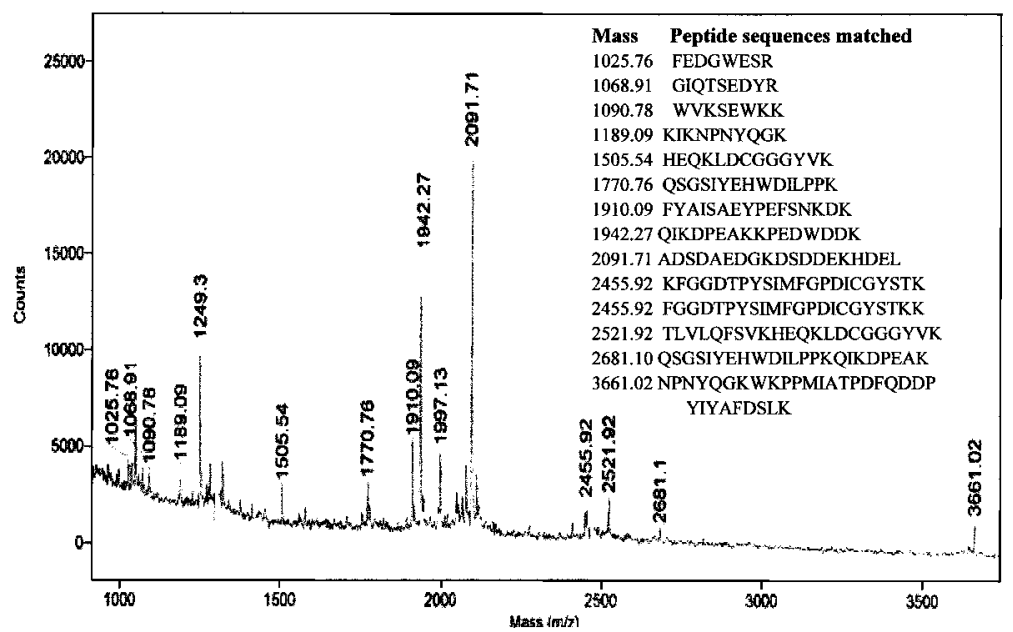

B

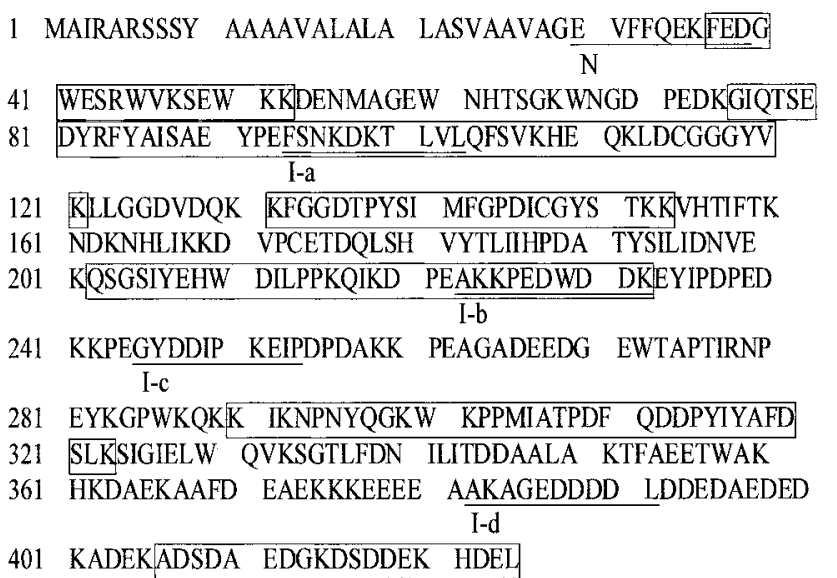

Fig. 3. Identification of Protein LS083

(A) MALDI-TOF-MS peptide mass fingerprint spectrum of a protein LS083. The protein LS083 was excised from 2-D PAGE gel and digested with trypsin. The peptides were extracted and their masses were measured by MADI-TOF MS, and the spectrum obtained was compared with MS databases and was matched to calreticulin from rice. (B) Amino acid sequence of protein LS083 matched to rice calreticulin. The five Edman sequence tags are indicated in the amino acid sequence by underline. Fourteen peptides were identified by MALDI-TOF-MS and are indicated in the amino acid sequence by open box. $\mathrm{N}$ : $\mathrm{N}$-terminal amino acid sequence. I: internal amino acid sequence.

I-c sequence GYDDIPKEIP (residues from 245 to 254), and the tag I-d sequence AKAGEDDDDL (residues from 382 to 391).

Calreticulin Participates with GAs in Controlling Rice Leaf-Sheath Elongation Whether or not the calreticulin protein level increases upon exogenous application of $\mathrm{GA}_{3}$ was examined by treating the leaf-sheath segments with $5 \mu \mathrm{M}$ $\mathrm{GA}_{3}$ for different time periods $(0,12,24$ and $48 \mathrm{~h})$, and immunoblot analyses with anti-calreticulin antibodies raised against the purified rice calreticulin were carried out. ${ }^{16}$ A clear band corresponding to an apparent molecular mass of $56 \mathrm{kDa}$ which, in turn, corresponded to the calreticulin was detected as shown in Figure 4A. However, no significant variation in the protein level was observed in leaf-sheaths treated with or without $\mathrm{GA}_{3}$, indicating that the shift observed on a 2-D PAGE (Fig. 2) might be the result of post translational modification of calreticulin protein. These results were further confirmed by CBB stained 2-D PAGE and by probing these gels with the anti-calreticulin antibodies (Figs. 4B and C). Interestingly, the expression level of LS079 increased and reached maximum within $48 \mathrm{~h}$ after $\mathrm{GA}_{3}$ treat- ment, however, LS083 showed a decrease in the protein level as the incubation time increased, exhibiting a decreased level of calreticulin expression at $48 \mathrm{~h}$ as evident from Figure 4A.

To determine the regulatory role of $\mathrm{GA}_{3}$ and to correlate the functional role of calreticulin during the second leafsheath elongation in the rice seedlings, Un-p, an inhibitor of $\mathrm{GA}_{3}$ biosynthesis, and ABA, a growth inhibitor, were supplemented with $\mathrm{GA}_{3}$ (Fig. 5). As expected, the second leafsheath elongated twice in the presence of $5 \mu \mathrm{M} \mathrm{GA}_{3}$ after 48 $\mathrm{h}$ of treatment as compared to control and/or in the presence of Un-p and ABA (Figs. 5A and B), indicating the role of $\mathrm{GA}_{3}$ in leaf-sheath elongation. The above samples when analyzed on 2-D PAGE showed a shift in the calreticulin from LS083 to LS079 only after treatment with GA $_{3}$, suggesting the possibility of a post-translational modification of calreticulin protein during leaf-sheath elongation.

Over-expressed Calreticulin Regulates Rice Growth To precisely determine the function of calreticulin in rice tissues, the full-length cDNA for calreticulin ${ }^{18)}$ was introduced into rice in the sense and antisense orientation under the control of the CaMV 35S promoter in the pIG121-Hm vector 
A

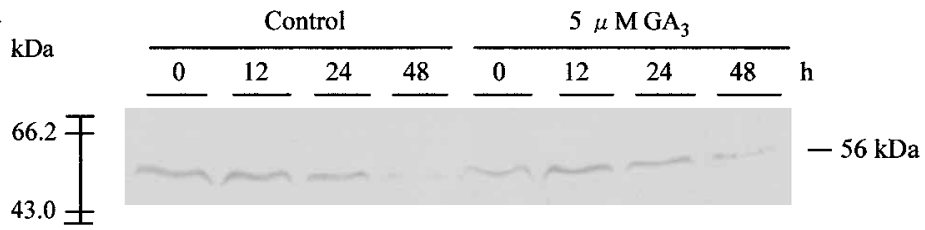

B
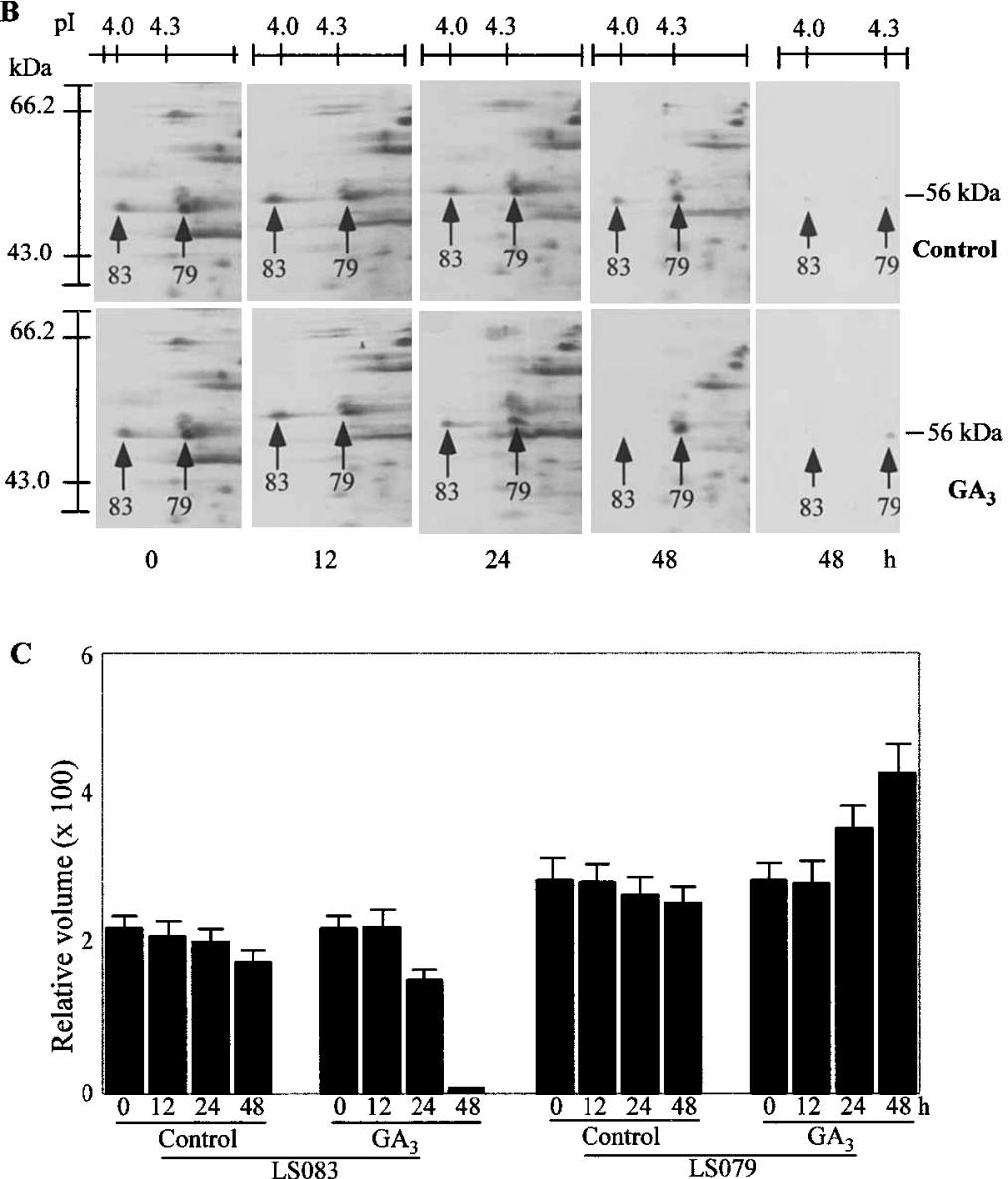

Fig. 4. Expression Analysis of Calreticulin in a Time Dependent Experiment of Leaf Sheath Treated with $5 \mu_{\mathrm{M}} \mathrm{GA}_{3}$

(A) Proteins were extracted from leaf sheath treated with $5 \mu \mathrm{M} \mathrm{GA}$ for 12, 24 and $48 \mathrm{~h}$, and separated by SDS-PAGE. Immunoblot analysis was performed with an anti-calreticulin antibody. The position of calreticulin is indicated at $56 \mathrm{kDa}$. (B and C) The time dependent changes in the amount of calreticulin in rice leaf sheath treated with $5 \mu \mathrm{M} \mathrm{GA}_{3}$. The total proteins separated by 2-D PAGE were stained with CBB. The patterns obtained for $48 \mathrm{~h}$ of GA -treated leaf sheath proteins were blotted onto PVDF membranes and then probed with antibody (pp56) raised against calreticulin. A shift from LS083 to LS079 occurred after treatment for $48 \mathrm{~h}$ in $\mathrm{GA}_{3}$ solution. Relative amount of protein spot was quantified using image analysis.

(Fig. 6A). Twenty independent lines of transgenic plants were regenerated and were confirmed by immunoblotting (Fig. 6D). The expression of calreticulin protein was more than double in calreticulin-sense transgenic rice leaf tissues as compared to control and antisense transgenic rice. Interestingly, the over-expression of calreticulin inhibited the callus regeneration and also the rate of seedling growth compared with the control and antisense rice (Figs. 6B, C).

\section{DISCUSSION}

The height of crop plants is often manipulated either genetically or by application of plant growth regulators to improve their agronomic traits. It is now well established that GAs are responsible for triggering stem or internodal elongation, as evident from the mutants impaired in GA biosynthesis or perception; ; ${ }^{1,2)}$ this is providing significant information on the involvement of different signaling components. In the present study, we have examined the proteome maps of rice leaf-sheath to analyze the proteins that are related to the $\mathrm{GA}_{3}$-response in its elongation.

The differential display of proteins with 2-D PAGE has facilitated analysis of the contribution of the proteins present in the rice leaf-sheath in response to $\mathrm{GA}_{3}$ (Fig. 2). The two different post separation techniques of Edman sequencing and MALDI-TOF MS, in conjunction with data base searching (Fig. 3), were used to assign putative identity to over 352 proteins from the leaf sheath. The magnitude of alteration in the change was demonstrated by the up-regulation of over 21 proteins and more than 11 proteins down-regulated, representing nearly $10 \%$ of the proteins modulated during leafsheath elongation.

The LS089 together with tubulin, the major constituent of microtubules, is involved in cell transport and cell division in 
$\mathbf{A}$

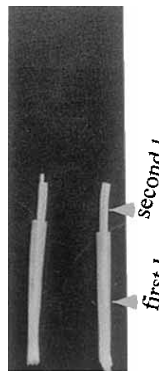

Control

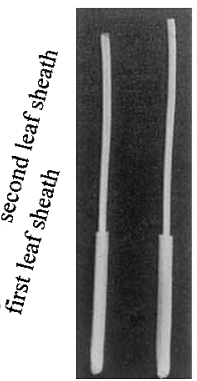

$\mathrm{GA}_{3}$

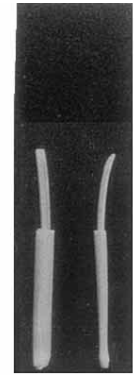

$\mathrm{GA}_{3}+\mathrm{Un}-\mathrm{p}$

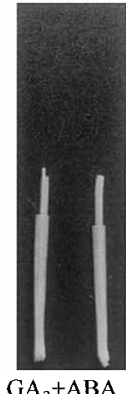

$\mathrm{GA}_{3}+\mathrm{ABA}$
B

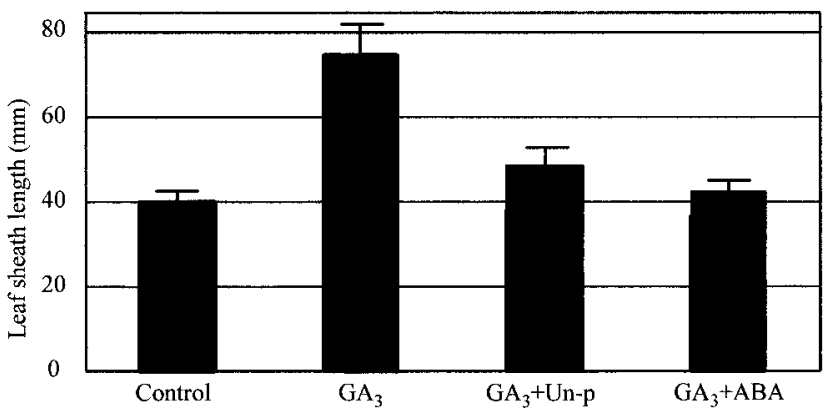

C
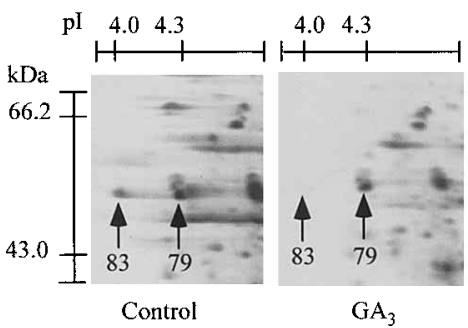
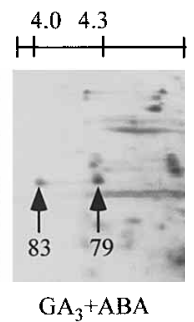

Fig. 5. The Effects of $\mathrm{GA}_{3}$, Un-p and ABA on Rice Leaf Sheath Elongation.

(A and B) The segments were collected from two-week-old leaf sheaths and then incubated in $5 \mu \mathrm{M} \mathrm{GA}$, either alone or supplemented with $0.34 \mu \mathrm{M}$ Un-p or $50 \mu \mathrm{M}$ ABA for $48 \mathrm{~h}$. In the presence of $\mathrm{GA}_{3}$, the second leaf sheath showed significant elongation, whereas in the presence of Un-p or ABA, no elongation was observed. (C) Proteins were extracted from leaf sheaths treated with $\mathrm{GA}_{3}$, Un-p or ABA, separated by 2-D PAGE, and were detected by CBB staining. The positions of LS083 and LS079 are marked by arrows to denote shift in calreticulin protein.

all eukaryotes. ${ }^{23)}$ LS093 and LS095 were identical to the ribulose-1,5-bisphosphate carboxylase/oxygenase (RuBisCO) large subunit, which is the key enzyme in carbon assimilation during photosynthesis. ${ }^{24)}$ The sequences of LS129 and LS162 were similar to that of RuBisCO activase, which was conserved in photosynthetic organisms across a wide range of genera, including lower eukaryotes. ${ }^{25)} \mathrm{RuBisCO}$ activase has recently been shown to function as the GA-binding protein in rice ${ }^{26)}$ inducing two independent cytosolic $\mathrm{Ca}^{2+}$ dependent protein kinase signaling components downstream to the RuBisCO, and suggesting their role in GA signaling. ${ }^{27)}$ LS208 matched the elongation factor from Taxeobacter ocellatus; this elongation factor promotes the GTP-dependent binding of aminoacyl-tRNA to the A-site of ribosomes during protein biosynthesis. ${ }^{28)}$ LS237 was identical to the oxygen-evolving enhancer protein-1 precursor from Triticum aestivum and stabilized the manganese cluster. ${ }^{29)}$ Proteins

A

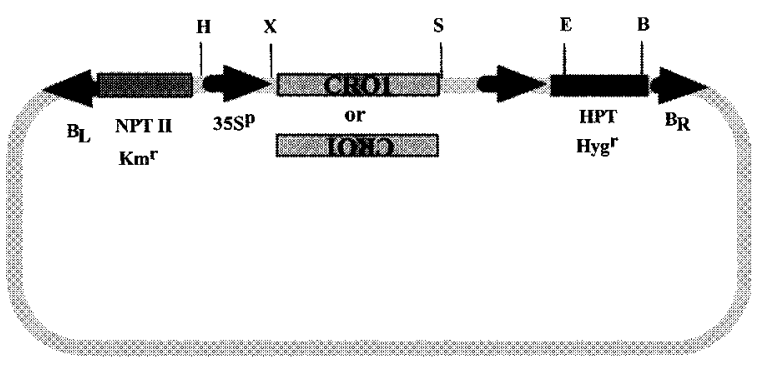

B

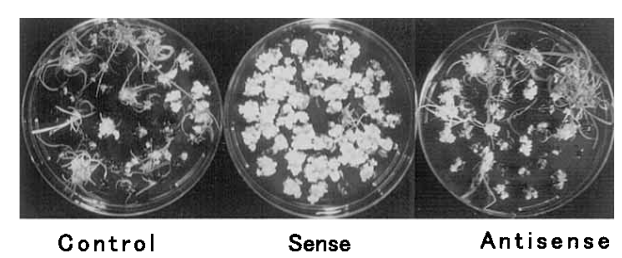

C

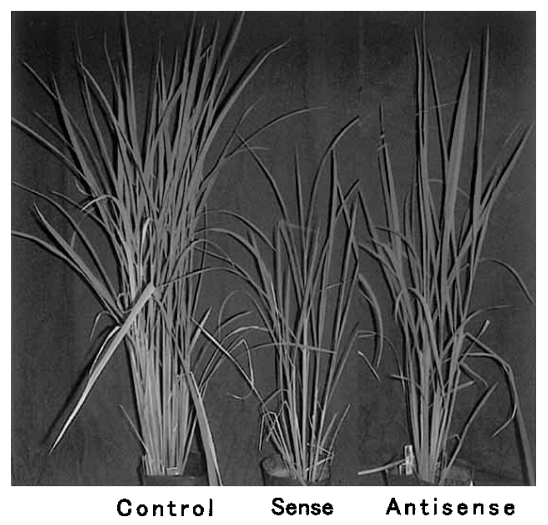

D

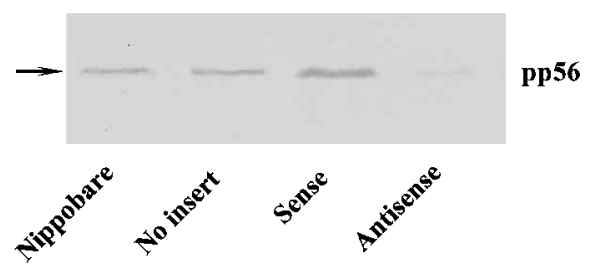

Fig. 6. Over-Expression of Calreticulin Inhibits the Regeneration and Growth

(A) Transformation of rice mediated by Agrobacterium tumefaciens strain EHA101. Rice calreticulin (CRO1) introduced downstream of the $35 \mathrm{~S}$ promoter in sense or antisense orientation in pIG121Hm, a binary vector that contains a kanamycin resistance gene (npt) and a hygromycin resistance gene (hpt), and the intron-gus in the T-DNA region. The following abbreviations are used for restriction enzyme cleavage sites: B, BamH I; E, EcoR I; H, Hind III; S, Sal I and X, Xba I. (B) The transformed calli were transferred to the regeneration medium. (C) After regeneration the transgenic rice were transferred to soil in pots and grown to maturity in a greenhouse. (D) Immunoblot analysis of calreticulin in leaf of CRO1 transgenic rice after cold treatment. The rice leaves from CRO1 sense, antisense and control (vector only) transgenic rice were separated by SDS-PAGE, and immunoblot analysis was performed with anti-calreticulin antibody as described in Materials and Methods. The position of calreticulin is indicated as pp56 $(56 \mathrm{kDa})$.

LS030 and LS034 were matched with heat-shock family proteins, namely endoplasmic reticulum (ER) and lumenal binding proteins (BiP), which act as molecular chaperones. ${ }^{30)}$ LS079 and LS083 were identical to calreticulin, which is a $\mathrm{Ca}^{2+}$-binding protein of the ER, and also functions as a molecular chaperone. ${ }^{31)}$

Changes in the protein levels alone do not imply changes in function, as many proteins are regulated by post translational modifications. It is possible that a post-translational 
modification, such as phosphorylation, may change in-gel migration of a protein spot such that a protein classified as down-regulated may in fact still be present elsewhere on the gel. As shown by the present study, through proteome analysis it is possible to precisely identify the modulation of calreticulin protein during leaf-sheath elongation in response to $\mathrm{GA}_{3}$. This protein showed an expected molecular mass of 56 $\mathrm{kDa}$, and was represented by twin spots on 2-D PAGE numbered LS079 and LS083 having an isoelectric point of 4.3 and 4.0, respectively. Calreticulin shifted from LS083 to LS079 after treatment with $\mathrm{GA}_{3}$, accompanied by the rice leaf-sheath elongation response (Figs. 4 and 5). A $56 \mathrm{kDa}$ protein having a $\mathrm{pI}$ of 4.5 , which is $\mathrm{pI} 4.3$ in this study, was phosphorylated in vitro in short-term cultured suspension cells, but no protein having pI 4.0 was phosphorylated. ${ }^{16)}$ Interestingly, no apparent shift in calreticulin was evident in the presence of $\mathrm{GA}_{3}$ inhibitors, suggesting the possibility of the change of phosphorylation of calreticulin during $\mathrm{GA}_{3}$ signal transduction during leaf-sheath elongation (Fig. 5). Calreticulin is a major $\mathrm{Ca}^{2+}$-sequestering protein found in eukaryotic cells, and has been implicated in a variety of cellular functions such as $\mathrm{Ca}^{2+}$ storage, signaling and chaperone activity. In mammalian cells, calreticulin contains putative recognition sequences for phosphorylation by protein kinase $\mathrm{C}$, casein kinase II, and tyrosine kinase, although no phosphorylation of calreticulin has been observed by protein kinase C. ${ }^{32}$ ) Moreover, in plants a potential site of phosphorylation by protein kinase casein kinase II is present at the C-terminal end of calreticulin, which is capable of undergoing phosphorylation. ${ }^{33)}$ Also, in pathogen-induced elicitor signaling, calreticulin was identified as one of the oligogalacturonidemodulated phospho-proteins in tobacco. ${ }^{34)}$ Other functional motifs in calreticulin include a nuclear targeting signal, a proline-rich region, acidic residues in the C-terminal, and an ER retention signal, suggesting the multiple functions of calreticulin might result from covalent modifications either by phosphorylation or calcium binding. ${ }^{35)}$

A previous study has shown the involvement of in vivo phosphorylation activity of calreticulin in long-term rice cultured suspension cells, but not in short-term cultured cells, ${ }^{16)}$ suggesting that a transient state of calreticulin might play an important role in signal transduction cascades by affecting the $\mathrm{Ca}^{2+}$ homeostasis during developmental regulation. This was further supported by transgenic rice expressing a sense and antisense gene of calreticulin, where the over-expression of calreticulin inhibited the callus regeneration and seedling growth (Fig. 6). There is already evidence that the concentration of internal $\mathrm{Ca}^{2+}$ and ATP affects the association of calreticulin with some proteins such as BiP, protein disulfide isomerase (PDI), calnexin and other peptides. ${ }^{36)}$ The binding site in calreticulin is localized to the proline-rich $\mathrm{P}$-domain that contains two sequence motifs and a high affinity $\mathrm{Ca}^{2+}$ binding site ${ }^{18)}$ indicating that calreticulin might be involved in the regulation of cellular or intercellular $\mathrm{Ca}^{2+}$ signaling.

Taken together with the results obtained through the proteome map of rice leaf-sheath, calreticulin appears to be an important component in the GA signaling pathway which regulates stem or internodal elongation in rice.

Acknowledgments S. Shen is a Japan Science and Tech- nology Agency Fellow from the Institute of Botany, Chinese Academy of Sciences in P. R. China. This work was supported by the Program for Promotion of Basic Research Activities for Innovative Biosciences and by a grant from rice genome project PR-1201, MAFF, JAPAN.

\section{REFERENCES}

1) Hooley R., Plant Mol. Biol., 26, 1529-1555 (1994).

2) Swain S. M., Olszewski N. E., Plant Physiol., 112, $11-17$ (1996).

3) Yamaguchi S., Kamiya Y., Plant Cell Physiol., 41, 251-257 (2000).

4) Lovegrove A., Hooley R., Trends Plant Sci., 5, 102-110 (2000).

5) Futsuhara Y., Kikuchi F., "Science of the Rice Plant", ed. by Matsuo T., Futsuhara Y., Kikuchi F., Yamaguchi H., Nobunkyo, Tokyo, 1997, pp. 300-317 (in Japanese).

6) Ueguchi-Tanaka M., Fujisawa Y., Kobayashi M., Ashikari M., Iwasaki Y., Kitano H., Matsuoka M., Proc. Natl. Acad. Sci. U.S.A., 97, $11638-11643$ (2000).

7) Ikeda A., Ueguchi-Tanaka M., Sonoda Y., Kitano H., Koshioka M., Futsuhara Y., Matsuoka M., Yamaguchi J., Plant Cell, 13, 999-1010 (2001).

8) Pandey A., Mann M., Nature (London), 405, 837-846 (2000).

9) Rossignol M., Curr. Opin. Biotechnol., 12, 131-134 (2001).

10) Jan van Wijk K., Trends Plant Sci., 5, 420-425 (2000).

11) Natera S. H., Guerreiro N., Djordjevic M. A., Mol. Plant Microbe. Interact., 13, 995-1009 (2000).

12) O' Farrell P. H., J. Biol. Chem., 250, 4007-4021 (1975).

13) Cleveland D. W., Fischer S. G., Kirschner M. W., Laemmli U. K., J. Biol. Chem., 252, $1102-1106$ (1997).

14) Pearson W. R., Lipman D. J., Proc. Natl. Acad. Sci. U.S.A., 85, 2444 2448 (1998).

15) Jensen O. N., Wilm M., Shevchenko A., Mann M., 112. "2-D Proteome Analysis Protocols," Humana Press Inc., Totowa, NJ, 1999, pp. $513-530$.

16) Komatsu S., Masuda T., Abe K., Plant Cell Physiol., 37, 748-753 (1996).

17) Hood E. E., Helmer G. L., Fraley R. T., Chilton M. D., J. Bacteriol., 168, 1291-1301 (1986).

18) Li Z., Komatsu S., Eur. J. Biochem., 267, 737-745 (2000).

19) Chilton M. D., Currier T. C., Farrand S. K., Bendich A. J., Gordon M. P., Nester E. W., Proc. Natl. Acad. Sci. U.S.A., 71, 3672-3676 (1974).

20) Hiei Y., Ohta S., Komari T., Kumashiro T., Plant J., 6, 271-282 (1994).

21) Sauter M., Mekhedov S. L., Kende H., Plant J., 7, 623-632 (1995).

22) Komatsu S., Kajiwara H., Hirano H., Theor. Appl. Genet., 86, 935942 (1993).

23) Nogales E., Annu. Rev. Biochem., 69, 277-302 (1998).

24) Morton B. R., Clegg M. T., Curr. Genet., 24, 357-365 (1993).

25) Neuwaid A. F., Aravind L., Spouge J. L., Koonin E. V., Genome Res., 9, 27-43 (1999).

26) Komatsu S., Matsuda T., Hirano H., FEBS Lett., 384, 167-171 (1996).

27) Sharma A., Komatsu S., Biochem. Biophys. Res. Commun., 290, 690695 (2002).

28) Ludwig W., Neumaier J., Klugbauer N., Brockmann E., Roller C., Jilg S., Reetz K., Schachtner I., Ludvigsen A., Bachleitner M., Antonie Van Leeuwenhoek., 64, 285-305 (1993).

29) Meadows J. W., Hulford A., Raines C. A., Robinson C., Plant Mol. Biol., 16, 1085-1087 (1991).

30) Martin J., J. Bioenerg. Biomembr., 29, 35-43 (1997).

31) Otteken A., Mass B., J. Biol. Chem., 271, 97-103 (1996).

32) Michalak M., Baksh S., Opas M., Exp. Cell Res., 197, 91-99 (1992).

33) Baldan B., Navazio L., Friso A., Mariani P., Meggio F., Biochem. Biophys. Res. Commun., 221, 498-502 (1996).

34) Droillard M. J., Guclu J., Caer J. P. L., Mathieu Y., Guern J., Lauriere C., Planta, 202, 341-348 (1997).

35) Kwon M. S., Park C. S., Choi K., Ahnn J., Kim J. I., Eom S. H., Kaufman S. J., Song W. K., Mol. Biol. Cell, 11, 1433-1443 (2000).

36) Corbett E. F., Oikawa K., Francois P., Tessier D. C., Kay C., Bergeron J. J., Thomas D. Y., Krause K. H., Michalak M., J. Biol. Chem., 274, $6203-6211$ (1999). 